\title{
Changes in Alveolar Prognathism and Anterior Teeth Protrusion in Japan
}

\author{
Yousuke Kaifu \\ Department of Anthropology, National Science Museum, Tokyo
}

(Submitted November 30, 1998; Review sent January 23, 1999; Accepted February 8, 1999)

\begin{abstract}
Temporal changes in alveolar prognathism and anterior protrusion of the anterior teeth were examined using adult Japanese skeletal materials from the following periods: Jomon, Yayoi, protohistoric Kofun, early medieval Kamakura, late medieval Muromachi, early modern Edo, and Recent. These samples are mainly from the Kanto region except for the Yayoi which derives from the northern Kyushu and Yamaguchi regions and the Recent whose geological origin is unknown.

The results indicated the existence of a subtle but nearly monotonous increase in alveolar prognathism through time, which is different from the previous interpretation. In contrast, the maxillary anterior teeth showed drastic changes toward a more protrusive condition from the Jomon to Kofun periods. The changes of this trait after the Yayoi period are small but it tends to become stronger through time. Causative factors of changes in anterior teeth protrusion were discussed.
\end{abstract}

Keywords: dento-facial morphology, Japanese, temporal change, ancient skeletal remains

\section{Introduction}

During the past 10,000 years, our species has experienced dramatic changes of living environment such as the Agricultural Revolution, urbanization, and the Industrial Revolution. These changes are considered to have influenced our body significantly in various ways. Documentation of these influences is critical in understanding our health and adaptive status, and this is greatly helped by investigation of temporal changes in skeletal morphology from past to present. As an attempt to understand one aspect of such influences, this study investigates temporal changes in alveolar prognathism and

Corresponding author: Yousuke Kaifu

Department of Anthropology, National Science Museum

3-23-1 Hyakunincho, Shinjuku-ku, Tokyo, 169-0073 Japan

TEL: +81-3-3364-2311 FAX: +81-3-3364-7104 Email: kaifu@kahaku.go.jp 
anterior protrusion of the anterior teeth using skeletal collections from Japan.

Prognathism refers to anterior protrusion of the jaw as a whole relative to the neurocranium while alveolar prognathism is defined as the condition where the alveolar process of the jaw bone alone protrudes forward. In this study, the 'maxillary' alveolar prognathism is brought into focus.

Martin (1928) calls the condition where teeth protrude anteriorly as 'prodentia'. The same condition is called by dentists 'labial inclination' or, for the incisors, 'incisor protrusion'. Since both the incisors and canines are examined in this study, the protrusive condition of these teeth is here termed 'anterior teeth protrusion'.

\section{Previous Research and Problems}

It is well know that alveolar prognathism and anterior teeth protrusion decrease through human evolutionary process during Plio-Pleistocene. On the other hand, information on the changes in these characters during Holocene is limited. In anthropology, (alveolar) prognathism have often been regarded as one of the marker characters in 'race' identification (Hooton, 1946; Montagu, 1960; Brues, 1977, and others). Moreover, because (alveolar) prognathism had once been regarded as reminiscent of our ancestors and strong expression of it in certain populations had been regarded as indicating the primitiveness of those groups; it had sometimes been utilized for ranking 'races' (Wolpoff and Caspari, 1996, p. 64). There is no doubt as to the existence of inter-population differences in the degree of alveolar prognathism and anterior teeth protrusion among modern humans. However, the possibility that alveolar prognathism is subject to environmental change has not been discussed.

Europe. Reports on temporal changes in alveolar prognathism or anterior teeth protrusion in Europe are few and the results available are not consistent. Because of this situation, the actual temporal changes of these traits in Europe are not clear from the literature.

Comparison of radiographs between a young adult skull sample from the Bronze Age Minoan civilization of Greece (1,800-1,200 B.C.) and living Greek children (10-14 years old) by Argyropoulos and others (1989) showed no significant changes in anterior teeth protrusion during this period. On the other hand, a comparison between medieval and modern Finnish samples by Varrela (1990) showed intensification of anterior teeth protrusion through time, represented by an increase of $8^{\circ}$ in the angle formed by the axis of the $\mathrm{I}^{1}$ and the nasal floor.

Japan. So far, the most substantial data on the changes in alveolar prognathism in a single region come from Japan. Unexpectedly, previous studies have shown that temporal changes in alveolar prognathism in the Japanese were not monotonous increase or decrease. Suzuki (1956a, 1969) was the first to indicate that, using materials mainly from the southern Kanto region (central Japan), alveolar prognathism was weak in the Jomon period, strengthened thereafter until the medieval Kamakura period, and weakened again toward modern times. Later, a similar trend was observed in the Kyushu region 
(western Japan) (Nakahashi and Nagai, 1985; Nakahashi, 1993; Sakuma, 1987). These findings suggest that this pattern of change might have been the same across Japan. However, these previous studies have several problems to be examined.

The most serious problem lies in the method of measurements. These studies based their arguments on the alveolar profile angle defined in Martin (1928) (No. 74). The appropriateness of this method as a parameter of alveolar prognathism is doubtful because this method utilizes the Frankfort horizontal $(F H)$ as a reference line and hence is influenced by various structural components of the cranium. Moreover, there may be another problem in the definition of a line representing the anterior surface of the maxillary alveolar process. One of the landmarks employed here, the nasospinale, is difficult to determine and subtle differences in recording result in significant displacement of this landmark in the antero-posterior direction. The nasospinale in the context of Martin's definition of the alveolar profile angle can also be read as being equal to the subspinale (Yamaguchi, 1997). However, individual variation in the development of the basal part of the anterior nasal spine is so great that in some individuals it reaches considerably down the inferior part of the alveolar process. In this case, this method is inappropriate especially in individuals who have a concave anterior surface of the alveolar process. In addition to the measurement methods, the previous studies failed to consider material selection criteria such as antemortem tooth loss. The assumption that alveolar prognathism (alveolar profile angle) can be regarded as representing anterior teeth protrusion is also problematic. This assumption is seen in many Japanese anthropological papers but there is no evidence to support this tacit understanding.

Using almost the same sample as Suzuki (1969), Kamegai and others (1982) concluded that anterior teeth protrusion in the maxilla is weak in the Jomon period and strengthens after the protohistoric Kofun period. Although this study is important in that it presents measurement data based on various reference lines on the cephalograms, the samples investigated were too small to draw a secure conclusion (around 10 for most of the chronological groups examined). Taking these problems into consideration, in the present study, new measurement methods are devised and temporal changes in alveolar prognathism and anterior teeth protrusion in the Japanese populations are re-examined.

\section{Materials and Methods}

Samples. The materials used in this study and other relevant information are tabulated in Table 1. Hereafter, the terms Jomon, Yayoi, Kamakura, Edo, and Recent are used in this paper to represent samples from the Jomon to Recent periods.

The Jomon is a pooled sample of materials from various regions in Japan. Studies on so far available Jomon materials throughout Japan have indicated a limited degree of regional variation in the morphology of various parts of the skeleton (Baba and Etoh, 1989; Dodo, 1982, 1986; Mouri, 1988; Naito and Matsushita, 1977; Nakahashi and Iizuka, 1998; Yamaguchi, 1981, 1982, 1989; Kaifu and others, 1998), including the 
Table 1 Materials used in this study

\begin{tabular}{|c|c|c|c|c|c|c|}
\hline \multirow{2}{*}{$\begin{array}{l}\text { Sample } \\
\text { name }^{a}\end{array}$} & \multirow{2}{*}{ Period } & \multirow{2}{*}{ Estimated age } & \multirow{2}{*}{ Region } & \multicolumn{2}{|c|}{$\mathrm{N}$} & \multirow{2}{*}{ Collection $^{\mathrm{b}}$} \\
\hline & & & & $\mathbf{M}$ & $\mathrm{F}$ & \\
\hline Jomon & $\begin{array}{l}\text { Jomon } \\
\text { (Prehistoric) }\end{array}$ & $\begin{array}{l}4000 \text { B.C. } \\
-300 \text { B.C. }\end{array}$ & $\begin{array}{l}\text { Hokkaido, Honshu, } \\
\text { and Kyushu }\end{array}$ & 50 & 20 & $\begin{array}{l}\text { TUM, } \\
\text { NSM }\end{array}$ \\
\hline Yayoi & $\begin{array}{l}\text { Yayoi } \\
\text { (Prehistoric) }\end{array}$ & $\begin{array}{l}300 \text { B.C. } \\
\text { - A.D. } 300\end{array}$ & $\begin{array}{l}\text { Northern Kyushu } \\
\text { and Yamaguchi }\end{array}$ & 29 & 18 & $\begin{array}{l}\text { Kyushu } \\
\text { Univ. }\end{array}$ \\
\hline Kofun & $\begin{array}{l}\text { Kofun - Heian } \\
\text { (Proto-early historic) }\end{array}$ & $\begin{array}{l}\text { A.D. } 300 \\
\quad \text { - A.D. } 900\end{array}$ & Kanto & 10 & 5 & $\begin{array}{l}\text { TUM, } \\
\text { NSM }\end{array}$ \\
\hline Kamakura & $\begin{array}{l}\text { Kamakura } \\
\text { (Early Medieval) }\end{array}$ & A.D. 1333 & Kanto & 52 & 23 & $\begin{array}{l}\text { TUM, } \\
\text { NSM }\end{array}$ \\
\hline Muromachi & $\begin{array}{l}\text { Muromachi } \\
\text { (Late Medieval) }\end{array}$ & $\begin{array}{l}\text { A.D. } 1333 \\
\text { - A.D. } 1568\end{array}$ & Kanto & 22 & 9 & $\begin{array}{l}\text { TUM, } \\
\text { NSM }\end{array}$ \\
\hline Edo & $\begin{array}{l}\text { Edo } \\
\text { (Pre-modern) }\end{array}$ & $\begin{array}{l}\text { A.D. } 1600 \\
\quad \text { - A.D. } 1868\end{array}$ & Tokyo & 39 & 30 & NSM \\
\hline Recent & $\begin{array}{l}\text { Meiji - Taisho } \\
\text { (Recent) }\end{array}$ & $\begin{array}{l}\text { A.D. } 1868 \\
\text { - A.D. } 1926\end{array}$ & Unknown & 32 & 16 & TUM \\
\hline
\end{tabular}

${ }^{a}$ The Kofun specimens were considered to have derived from a somewhat upper-class people (Terakado, 1981), while the other samples represented more common people (Suzuki, 1969). ${ }^{\mathrm{b}} \mathrm{TUM}=$ University Museum, Univ. of Tokyo, NSM=National Science Museum, Tokyo.

mandible (Kaifu, 1995) and teeth (Matsumura, 1989). The major portion of the present materials is from shell-mounds of the Middle to Final Jomon periods (ca. 3,000 BC - 300 $\mathrm{BC}$ ) along the coast of the Kanto region.

The populations comprising the present Yayoi sample is considered to be immigrants from the Asian continent or their offspring (Nakahashi, 1993; Nakahashi and Iizuka, 1998, and others). Recent studies have shown that the later Mainland Japanese evolved through the mixture of this population and native Jomon people, possibly with greater influence from the former (for example, Yamaguchi, 1982; Hanihara, 1991; Omoto and Saitou, 1997; see Kaifu, 1997 for details).

The Kofun sample mainly consists of materials from cave type burials (yokoana) of 7-8 C. The entire Kamakura sample is derived from the Zaimokuza site in the southern Kanto region, which is considered to have been a temporary mass burial for war dead from a battle in 1333. This sample is not regarded as that of a small local population but as including remains of soldiers and their servants gathered from other areas in the Kanto region (Mikami, 1956). The major portion of the Muromachi sample is from the southern Kanto region. The Edo sample consists of remains from ordinary burials excavated in the city of Edo (present Tokyo). The Recent sample is comprised of specimens derived from 
dissecting rooms. Although the provenance of the Recent specimens is unknown, they are similar at least in mandibular morphology to a contemporary population in the Kanto region (Kaifu, 1997).

Measurements. All the measurements were taken from lateral photographs. The reference lines were defined on the photographs as below and in Figure 1, and measurements were defined as in Table 2. Two reference lines were defined as straight lines passing through two landmarks, respectively, but it was difficult for the other reference lines to determine such landmarks. Because of this, they were defined as the straight lines that represent most appropriately the overall inclination of a more or less curved contour of a certain part of the maxilla and teeth (AAL 2, UIL, LIL, UCL, LCL; see below and Figure 2).

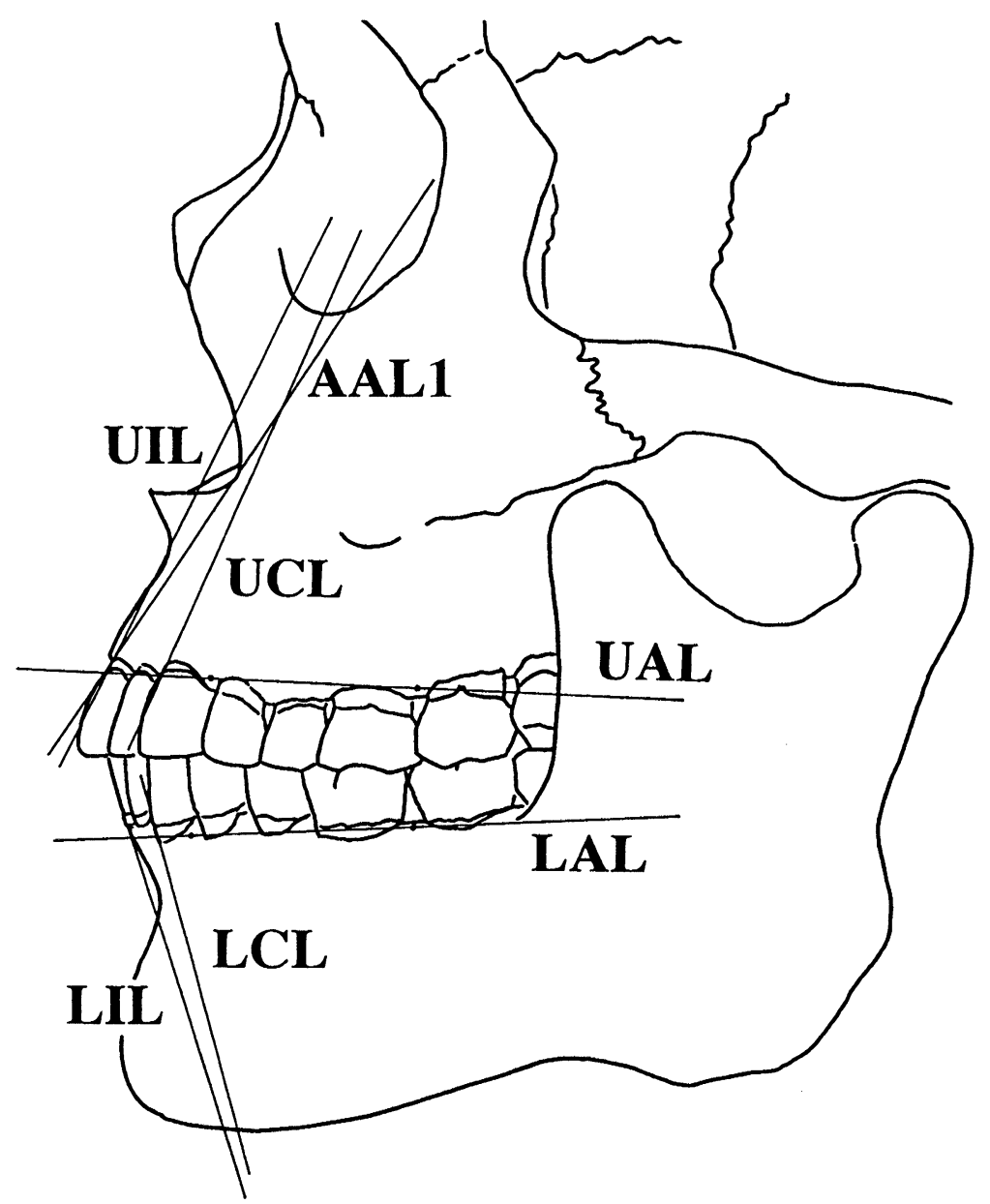

Figure 1 Reference lines used in this study. 

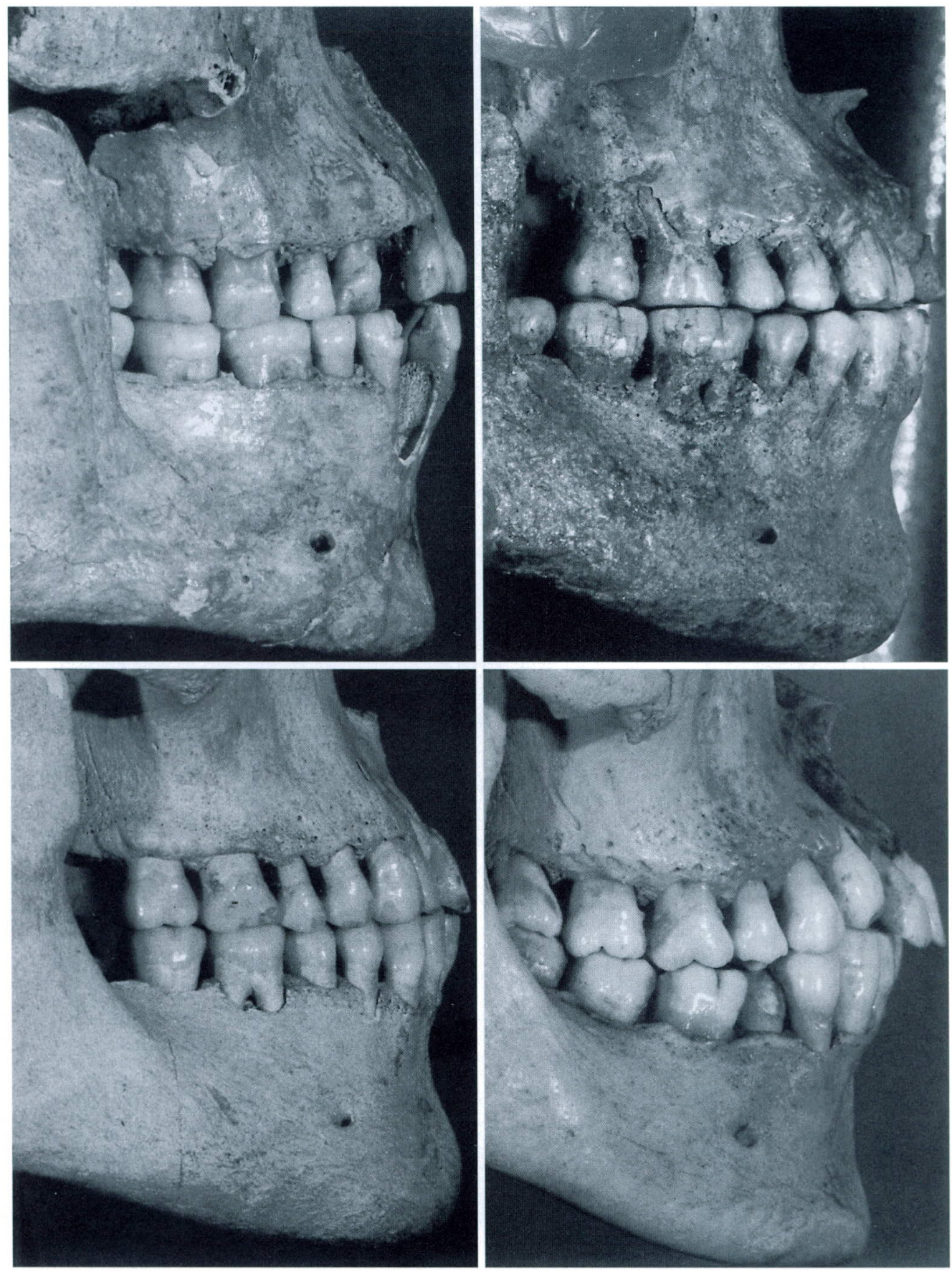

Figure 2 Photographs used for the measurements in this study. Those specimens showing average conditions in alveolar prognathism and anterior teeth protrusion in each sample were selected. Upper left, Jomon (No. 131734, University of Tokyo); upper right, Yayoi (Kanenokuma 119, Kyushu University); lower right, Kamakura (Zaimokuza 70, Tokyo University); lower left, Modern Japanese (No. 2159, University of Tokyo). 
Table 2 List of measurements

\begin{tabular}{ll}
\hline \multicolumn{1}{c}{ Measurements } & \multicolumn{1}{c}{ Definition } \\
\hline Alveolar inclination angle 1 & Angle formed by AAL1 and UAL \\
Alveolar inclination angle 2 & Angle formed by AAL2 and UAL \\
Alveolar profile angle 1 & Angle formed by AAL1 and FH \\
Alveolar profile angle 2 & Angle formed by AAL2 and FH \\
FH/UAL angle & Angle formed by FH and UAL \\
$\mathrm{I}^{1}$ inclination angle & Angle formed by UIL and UAL \\
$\mathrm{C}^{1}$ inclination angle & Angle formed by UCL and UAL \\
$\mathrm{I}_{1}$ inclination angle & Angle formed by LIL and LAL \\
$\mathrm{C}_{1}$ inclination angle & Angle formed by LCL and LAL \\
Inter-incisal angle & Angle formed by UIL and LIL \\
Inter-canine angle & Angle formed by UCL and LCL \\
AAL1/UIL angle & Angle formed by AAL1 and UIL \\
AAL2/UIL angle & Angle formed by AAL2 and UIL \\
\hline
\end{tabular}

\section{Upper (Lower) alveolar line (UAL or LAL)}

The straight line passing through the point situated on the border between the lateral and inferior (superior) surfaces of the alveolar process at $\mathrm{C} / \mathrm{P} 1$, and the similar point at M1/M2. This line was judged, as a result of the examination of a number of photographs, to represent the alveolar line more appropriately compared to the other lines passing through the other pairs of points. If one of these landmarks is missing or dislocated from where it should be by local diseases and so on, the similar point at the neighboring area was used as a substitute.

\section{Anterior alveolar line 1 ( $A A L 1)$}

The straight line passing through the most anterior point on the border between the maxillary alveolar bone and $\mathrm{I}^{1}$, tangent to the infero-posterior margin of the nasal orifice. The inferior landmark was chosen as a substitute for the prosthion which can hardly be identified on a lateral photograph.

\section{Anterior alveolar line $2(A A L 2)$}

The straight line that represents the inclination of the midsagittal contour of the anterior surface of the maxillary alveolar bone inferior to the base of the anterior nasal spine.

Upper (Lower) incisor line (UIL or LIL)

The straight line representing the inclination of the contour of the anterior surface of $I^{1}\left(I_{1}\right)$ root that exposes from the alveolar bone. The portion of the root contour refereed was restricted to the cervical portion (up to about $3 \mathrm{~mm}$ distance in actual size from the cervix).

Upper (Lower) canine line (UCL or LCL)

The line that represents the inclination of $\mathrm{C}^{1}\left(\mathrm{C}_{1}\right)$. Comparable to the UIL and LIL. The photographs were magnified 1.5 times real size when printed. Photography was 
conducted using a telephoto lens with a focal distance of $300 \mathrm{~mm}$ (Nikkor $300 \mathrm{~mm}$ ) and an extension ring (Nikon PK-13), keeping the distance between the subject and camera $3 \mathrm{~m}$ to minimize the parallax effect. Original specimens and frontal photographs were referred when the landmarks were unclear on the lateral photographs. The measurements from the better-preserved side were used for analyses but those from the left side were used if the preservation of both sides was similar. All the specimens were checked for distortion and damage. Poorly reconstructed specimens were corrected if possible, and the author newly reconstructed several specimens.

As mentioned above, a measurement of alveolar prognathism using the $F H$ as reference line has defects that it is potentially affected by morphological variation in various components of the cranium. One reasonable reference component on which measurements of alveolar prognathism and anterior teeth protrusion should be based is the dentition seen in lateral view. The measurements adopted in this study are considered to represent the orientation of the dentition satisfactorily. In addition, they are comparatively free from the problem of preservation compared with other alternatives such as the palatal line, and hence increase the sample size considerably. The occusal line (plane) is not used as the reference line because of the existence of great inter-populational variation in the bite form in the sample studied. The Jomon materials normally show edge-to-edge bite while incisor overlapping is overwhelming in the Kofun and later populations (Suzuki, 1969; Seguchi, 1998; Kaifu, unpublished data). The mandibular basal line is frequently utilized for the reference line in measuring inclination of the axis of the $\mathrm{I}_{1}$. This method was, however, not adopted because, in populations after the Edo period, reduction in the gonial region of the mandible is strongly suspected to have occurred owing to underdevelopment caused by reduction of masticatory activities (Kaifu, 1997).

Inclination of the anterior surface of the maxillary alveolar process was defined in two ways ( $A A L 1$ and $A A L 2$ ). The $A A L 2$ is the same method as that used in one of the previous studies (Nakahashi, 1993). The $A A L 1$ that is newly defined in this study is free from the problem of individual variation in development of the base of the anterior nasal spine (see above). In addition, it is the author's impression that this method represents the inclination of the anterior surface of the maxillary alveolar process fairly well when supposing that the pyramidal projection of the anterior nasal spine was removed from the surface.

The most popular definition of the axis of the I1 is the line passing through the root apex and cutting edge of the crown. This definition was not adopted here since this study is not based on radiographs but is based on photographs to utilize the alveolar lines ( $U A L$ and $L A L)$ as reference lines. In addition, the determination of the cutting edge of the crown is impossible for severely worn teeth. To examine the differences between the UIL of the present study and the axis of this ordinal method, midsagittal cross-section of 28 relatively unworn $I^{1}$ s (specimens from the Jomon, Kamakura, and Edo) were prepared by cutting plaster casts of them. The angle formed by these two lines showed 
the mean of $5.3^{\circ}$, a standard deviation of 2.9 (range $0.5^{\circ}-14^{\circ}$ ), and a kurtosis of 1.58 .

Material selection. Antemortem tooth loss, significant loss of the crown by caries, and tooth disposition due to periodontitis may affect the original dento-facial morphology. Among dentally adult specimens with not more than three such abnormal teeth in both maxillary and mandibular dentitions anterior to the third molars, those judged as preserving unaffected dento-facial morphology at least on one side were selected. In addition, among specimens whose mandible is missing, those with an intact maxillary dentition anterior to the third molars were added to the sample if there was no sign of the existence of abnormal teeth in the missing mandible. This judgement was done on the basis of continuity and symmetry of occlusal wear and presence or absence of extraerupted teeth in the maxillary dentition. Extraeruption of a tooth occurs when it loses its antagonist(s) (Anneroth and Ericson, 1967; Compagnon and Wada, 1991) and hence is a useful indicator of antemortem tooth loss in the opposing dentition.

Every specimen with a retained deciduous tooth, a supernumerary tooth, or a congenitally missing tooth was excluded. Among the entire materials selected, about $56 \%$ were essentially complete specimens with no abnormal teeth in the maxillary and mandibular dentitions anterior to the third molars, while about $26 \%$ were those who have a few abnormal teeth and the remaining $18 \%$ were specimens with missing mandible.

Sex determination. Sexes were determined by the author mainly based on the pelvis and cranial morphology.

Analyses. Only univariate analyses were conducted because the number of specimens with no missing data is limited. One-way ANOVA as well as Tukey's test were applied for the test of differences in the means among populations. All the statistical procedures were conducted using SYSTAT 5.2.1 for Macintosh (SYSTAT, Inc., 1992).

\section{Results}

Descriptive statistics and results of statistical tests are shown in Table 3. Figure 3 shows temporal changes of the means of selected measurements for populations whose sample sizes are relatively large.

Concerning alveolar inclination angle 1, the Recent male is significantly smaller than most of the other male groups. Although differences in this measurement are not significant in the other population pairs, the Jomon tends to be slightly larger than the others in both sexes if several groups with small sample size are excluded from consideration. A similar tendency is observed more clearly in the alveolar inclination angle 2. Concerning the alveolar profile angle (1 and 2) that uses the $F H$ as the reference line, the Kamakura and Muromachi is slightly smaller than the others (the Recent is also smaller in the males). The above four measurements show sex differences in that the females tend to be smaller than the males. These differences are statistically significant (t-test, significance level $=0.05$ ) in most of the four measurements in the Yayoi, Kamakura, Muromachi, and Edo. Although being statistically not significant, the Jomon, Kofun, Kamakura, and Muromachi are slightly smaller in FH/UAL angle than in 
Table 3a Comparison of the measurements (males) ${ }^{a}$

\begin{tabular}{|c|c|c|c|c|c|c|c|c|c|c|c|c|}
\hline & \multicolumn{4}{|c|}{$\begin{array}{l}\text { Alveolar inclination angle } 1 \\
\mathrm{~F}=3.21, \mathrm{P}=0.00\end{array}$} & \multicolumn{4}{|c|}{$\begin{array}{l}\text { Alveolar inclination angle } 2 \\
\mathrm{~F}=6.24, \mathrm{P}=0.00\end{array}$} & \multicolumn{4}{|c|}{$\begin{array}{l}\text { Alveolar profile angle } 1 \\
F=2.60, P=0.02\end{array}$} \\
\hline & $\mathrm{N}$ & Mean & S.D. & $\begin{array}{l}\text { Pops. with } \\
\text { signif. diff. }\end{array}$ & $\mathrm{N}$ & Mean & S.D. & $\begin{array}{l}\text { Pops. with } \\
\text { signif. diff. }\end{array}$ & $\mathrm{N}$ & Mean & S.D. & $\begin{array}{l}\text { Pops. with } \\
\text { signif. diff. }\end{array}$ \\
\hline Jomon & 45 & 58.9 & 6.3 & $\mathrm{R}$ & 40 & 68.4 & 7.2 & $\mathrm{Ka}, \mathrm{E}, \mathrm{N}$ & 18 & 64.1 & 4.9 & \\
\hline Yayoi & 27 & 57.9 & 5.2 & $\mathrm{R}$ & 28 & 64.5 & 6.9 & $\mathrm{R}$ & 22 & 64.1 & 4.8 & \\
\hline Kofun & 10 & 58.7 & 4.6 & & 8 & 62.7 & 5.8 & & 7 & 65.8 & 3.9 & \\
\hline Kamakura & 51 & 57.0 & 6.0 & & 44 & 63.1 & 9.1 & $\mathrm{~J}, \mathrm{R}$ & 32 & 61.0 & 6.6 & \\
\hline Muromachi & 20 & 58.2 & 3.4 & & 19 & 62.9 & 6.0 & & 18 & 62.8 & 4.8 & \\
\hline Edo & 38 & 57.6 & 4.5 & $\mathrm{R}$ & 36 & 62.6 & 6.1 & $\mathrm{~J}$ & 34 & 64.6 & 3.6 & \\
\hline \multirow[t]{3}{*}{ Recent } & 32 & 53.8 & 5.3 & $\mathrm{~J}, \mathrm{Y}, \mathrm{E}$ & 32 & 57.9 & 8.0 & $\mathrm{~J}, \mathrm{Y}, \mathrm{Ka}$ & 32 & 61.4 & 5.5 & \\
\hline & \multicolumn{4}{|c|}{$\begin{array}{c}\text { Alveolar profile angle } 2 \\
\mathrm{~F}=2.91, \mathrm{P}=0.00\end{array}$} & \multicolumn{4}{|c|}{$\begin{array}{r}\mathrm{FH} / \mathrm{UAL} \text { angle } \\
\mathrm{F}=2.68, \mathrm{P}=0.02\end{array}$} & \multicolumn{4}{|c|}{$\begin{array}{c}\mathrm{I}^{1} \text { inclination angle } \\
\mathrm{F}=9.54, \mathrm{P}=0.00\end{array}$} \\
\hline & $\mathrm{N}$ & Mean & S.D. & $\begin{array}{l}\text { Pops. with } \\
\text { signif. diff. }\end{array}$ & $\mathrm{N}$ & Mean & S.D. & $\begin{array}{l}\text { Pops. with } \\
\text { signif. diff. }\end{array}$ & $\mathrm{N}$ & Mean & S.D. & $\begin{array}{l}\text { Pops. with } \\
\text { signif. diff. }\end{array}$ \\
\hline Jomon & 17 & 73.9 & 6.6 & $\mathrm{R}$ & 18 & 4.7 & 5.3 & & 39 & 73.1 & 12.2 & $\mathrm{~K} 0, \mathrm{Ka}, \mathrm{E}, \mathrm{R}$ \\
\hline Yayoi & 22 & 70.2 & 6.4 & & 22 & 7.1 & 4.1 & & 23 & 66.0 & 11.6 & $\mathrm{R}$ \\
\hline Kofun & 6 & 70.6 & 7.8 & & 7 & 5.9 & 3.9 & & 10 & 62.0 & 7.4 & $\mathrm{~J}$ \\
\hline Kamakura & 30 & 67.9 & 9.5 & & 32 & 4.4 & 4.2 & $\mathrm{R}$ & 46 & 60.5 & 9.2 & $\mathbf{J}$ \\
\hline Muromachi & 16 & 67.3 & 6.6 & & 18 & 4.8 & 3.8 & & 6 & 60.8 & 12.6 & \\
\hline Edo & 34 & 69.7 & 5.4 & & 34 & 6.7 & 3.8 & & 34 & 60.9 & 7.9 & J \\
\hline \multirow[t]{3}{*}{ Recent } & 32 & 65.5 & 7.9 & $\mathbf{J}$ & 32 & 7.6 & 3.7 & $\mathrm{Ka}$ & 27 & 56.6 & 9.2 & $\mathrm{~J}, \mathrm{Y}$ \\
\hline & \multicolumn{4}{|c|}{$\begin{array}{c}\mathrm{C}^{1} \text { inclination angle } \\
\mathrm{F}=2.65, \mathrm{P}=0.02\end{array}$} & \multicolumn{4}{|c|}{$\begin{array}{c}\mathrm{I}_{1} \text { inclination angle } \\
\mathrm{F}=5.35, P=0.00\end{array}$} & \multicolumn{4}{|c|}{$\begin{array}{c}\mathrm{C}_{1} \text { inclination angle } \\
\mathrm{F}=2.02, \mathrm{P}=0.07\end{array}$} \\
\hline & $\mathrm{N}$ & Mean & S.D. & $\begin{array}{l}\text { Pops. with } \\
\text { signif. diff. }\end{array}$ & $\mathrm{N}$ & Mean & S.D. & $\begin{array}{l}\text { Pops. with } \\
\text { signif. diff. }^{\text {b }}\end{array}$ & $\mathrm{N}$ & Mean & S.D. & $\begin{array}{l}\text { Pops. with } \\
\text { signif. diff. }\end{array}$ \\
\hline Jomon & 38 & 76.1 & 9.2 & $\mathrm{E}, \mathrm{R}$ & 29 & 82.8 & 7.4 & $\mathrm{Y}, \mathrm{Ka}, \mathrm{E}, \mathrm{R}$ & 33 & 84.3 & 6.0 & $\mathrm{R}$ \\
\hline Yayoi & 23 & 73.5 & 6.5 & & 16 & 76.0 & 5.9 & $\mathrm{~J}$ & 15 & 81.5 & 4.6 & \\
\hline Kofun & 9 & 73.1 & 7.4 & & 5 & 74.9 & 7.7 & & 6 & 82.8 & 7.7 & \\
\hline Kamakura & 47 & 73.6 & 6.2 & & 18 & 72.8 & 6.0 & $\mathrm{~J}$ & 25 & 80.4 & 5.9 & \\
\hline Muromachi & 4 & 75.0 & 7.6 & & 2 & 76.8 & 1.8 & & 2 & 78.8 & 3.2 & \\
\hline Edo & 34 & 71.3 & 6.0 & $\mathrm{~J}$ & 26 & 75.5 & 7.5 & $\mathrm{~J}$ & 35 & 83.0 & 7.3 & \\
\hline \multirow[t]{3}{*}{ Recent } & 28 & 69.9 & 6.0 & $\mathrm{~J}$ & 21 & 73.9 & 7.3 & $\mathrm{~J}$ & 24 & 79.2 & 6.2 & $\mathrm{~J}$ \\
\hline & \multicolumn{4}{|c|}{$\begin{array}{l}\text { Inter-incisal angle } \\
F=14.17, P=0.00\end{array}$} & \multicolumn{4}{|c|}{$\begin{array}{l}\text { Inter-canine angle } \\
\mathrm{F}=5.32, \mathrm{P}=0.00\end{array}$} & \multicolumn{4}{|c|}{$\begin{array}{c}\left(\mathrm{I}^{1} \text { inc. ang. }\right)-\left(\mathrm{I}_{1} \text { inc. ang. }\right) \\
\mathrm{F}=1.21, \mathrm{P}=0.31\end{array}$} \\
\hline & $\mathrm{N}$ & Mean & S.D. & $\begin{array}{l}\text { Pops. with } \\
\text { signif. diff. }\end{array}$ & $\mathrm{N}$ & Mean & S.D. & $\begin{array}{l}\text { Pops. with } \\
\text { signif. diff. }^{b}\end{array}$ & $\mathrm{~N}$ & Mean & S.D. & $\begin{array}{l}\text { Pops. with } \\
\text { signif. diff. }\end{array}$ \\
\hline Jomon & 25 & 152.0 & 16.5 & All but $\mathrm{M}$ & 31 & 156.2 & 12.0 & $\mathrm{Ka}, \mathrm{E}, \mathrm{R}$ & 24 & 9.2 & 10.2 & \\
\hline Yayoi & 13 & 131.4 & 13.6 & $\mathrm{~J}$ & 14 & 148.6 & 7.9 & & 13 & 12.2 & 13.4 & \\
\hline Kofun & 5 & 129.1 & 8.4 & $\mathrm{~J}$ & 5 & 147.1 & 7.5 & & 5 & 12.1 & 14.6 & \\
\hline Kamakura & 18 & 125.4 & 8.4 & $\mathrm{~J}$ & 21 & 146.8 & 6.8 & $\mathrm{~J}$ & 18 & 13.7 & 9.5 & \\
\hline Muromachi & 2 & 132.0 & 15.6 & & 2 & 143.5 & 13.4 & & 2 & 13.0 & 11.3 & \\
\hline Edo & 25 & 127.4 & 10.8 & $\mathrm{~J}$ & 34 & 145.5 & 10.2 & $\mathrm{~J}$ & 24 & 15.1 & 11.4 & \\
\hline Recent & 18 & 122.8 & 9.9 & $\mathbf{J}$ & 22 & 142.5 & 9.0 & $\mathrm{~J}$ & 18 & 17.5 & 7.6 & \\
\hline
\end{tabular}


Table 3a (continued) ${ }^{\mathrm{a}}$

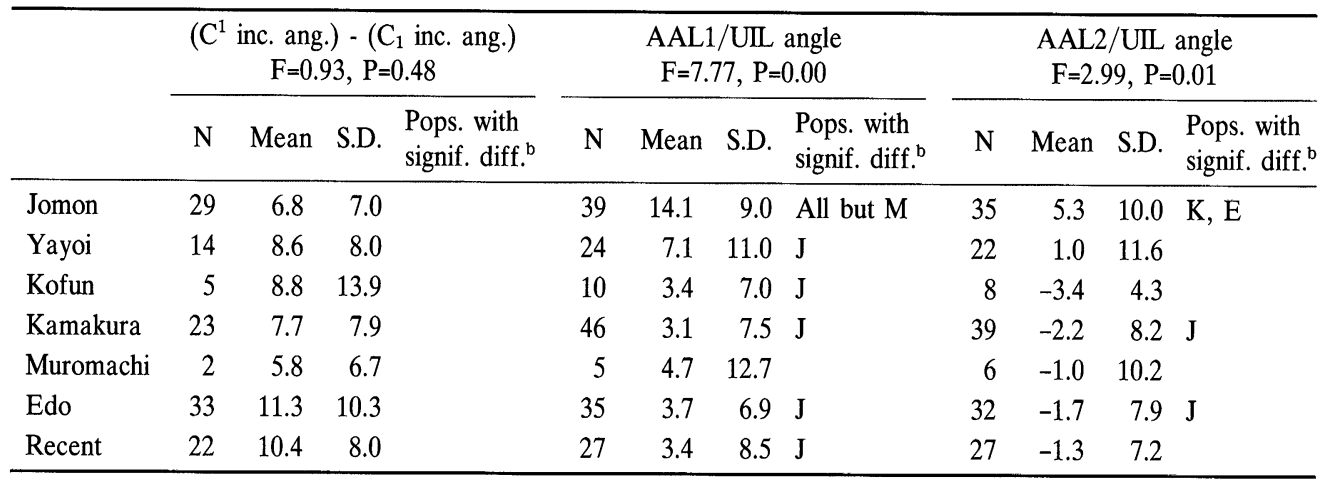

${ }^{a}$ Descriptive statistics and the result of statistical tests (results of the one-way ANOVA below the measurement names and those of the Tukey's test at the right columns).

${ }^{\mathrm{b}}$ The letters indicate population(s) whose mean is significantly different $(\mathrm{P}<0.05)$ from that of the population listed to the left. $\mathrm{J}=\mathrm{J}$ Jomon, $\mathrm{Y}=$ Yayoi, Ko=Kofun, $\mathrm{Ka}=$ Kamakura, M=Muromachi, E=Edo, $\mathrm{R}=$ Recent.

Table 3b Comparisons of the measurements (females) ${ }^{\mathrm{a}}$

\begin{tabular}{|c|c|c|c|c|c|c|c|c|c|c|c|c|}
\hline & \multicolumn{4}{|c|}{$\begin{array}{l}\text { Alveolar inclination angle } 1 \\
\qquad \mathrm{~F}=1.42, \mathrm{P}=0.21\end{array}$} & \multicolumn{4}{|c|}{$\begin{array}{l}\text { Alveolar inclination angle } 2 \\
\qquad \mathrm{~F}=5.96, \mathrm{P}=0.00\end{array}$} & \multicolumn{4}{|c|}{$\begin{array}{c}\text { Alveolar profile angle } 1 \\
F=1.24, P=0.29\end{array}$} \\
\hline & $\mathrm{N}$ & Mean & S.D. & $\begin{array}{l}\text { Pops. with } \\
\text { signif. diff. }\end{array}$ & $\mathrm{N}$ & Mean & S.D. & $\begin{array}{l}\text { Pops. with } \\
\text { signif. diff. }\end{array}$ & $\mathrm{N}$ & Mean & S.D. & $\begin{array}{l}\text { Pops. with } \\
\text { signif. diff. }\end{array}$ \\
\hline Jomon & 19 & 56.6 & 5.1 & & 16 & 66.7 & 5.9 & All but Ko & 8 & 62.3 & 5.7 & \\
\hline Yayoi & 18 & 54.6 & 4.3 & & 15 & 59.1 & 4.7 & $\mathrm{~J}$ & 13 & 62.4 & 4.8 & \\
\hline Kofun & 5 & 58.9 & 5.7 & & 5 & 60.9 & 4.8 & & 4 & 65.1 & 4.4 & \\
\hline Kamakura & 20 & 54.0 & 5.9 & & 19 & 56.8 & 6.2 & $\mathrm{~J}$ & 13 & 58.7 & 4.9 & \\
\hline Muromachi & 9 & 52.7 & 4.4 & & 9 & 57.3 & 5.4 & $\mathbf{J}$ & 9 & 58.9 & 3.5 & \\
\hline Edo & 30 & 53.7 & 6.2 & & 30 & 56.1 & 8.7 & $\mathrm{~J}$ & 30 & 60.4 & 6.3 & \\
\hline \multirow[t]{3}{*}{ Recent } & 16 & 53.8 & 4.7 & & 16 & 55.4 & 4.6 & $\mathrm{~J}$ & 16 & 61.8 & 6.0 & \\
\hline & \multicolumn{4}{|c|}{$\begin{array}{c}\text { Alveolar profile angle } 2 \\
\mathrm{~F}=4.30, \mathrm{P}=0.00\end{array}$} & \multicolumn{4}{|c|}{$\begin{array}{l}\text { FH/UAL angle } \\
\mathrm{F}=0.70, \mathrm{P}=0.65\end{array}$} & \multicolumn{4}{|c|}{$\begin{array}{c}\mathrm{I}^{1} \text { inclination angle } \\
\mathrm{F}=11.75, \mathrm{P}=0.00\end{array}$} \\
\hline & $\mathrm{N}$ & Mean & S.D. & $\begin{array}{l}\text { Pops. with } \\
\text { signif. diff. }^{b}\end{array}$ & $\mathrm{~N}$ & Mean & S.D. & $\begin{array}{l}\text { Pops. with } \\
\text { signif. diff. }\end{array}$ & $\mathrm{N}$ & Mean & S.D. & $\begin{array}{l}\text { Pops. with } \\
\text { signif. diff. }\end{array}$ \\
\hline Jomon & 8 & 74.6 & 7.2 & $\mathrm{Ka}, \mathrm{M}, \mathrm{E}, \mathrm{R}$ & 8 & 6.1 & 5.9 & & 14 & 73.8 & 9.9 & All but $\mathrm{M}$ \\
\hline Yayoi & 12 & 67.2 & 3.9 & & 13 & 7.3 & 3.2 & & 15 & 55.6 & 7.0 & $\mathrm{~J}$ \\
\hline Kofun & 4 & 67.0 & 1.8 & & 4 & 5.0 & 5.6 & & 4 & 58.0 & 4.0 & $\mathrm{~J}$ \\
\hline Kamakura & 12 & 62.1 & 4.4 & $\mathrm{~J}$ & 13 & 5.3 & 3.5 & & 16 & 55.3 & 8.6 & $\mathrm{~J}$ \\
\hline Muromachi & 9 & 63.4 & 5.6 & $\mathbf{J}$ & 9 & 6.2 & 3.6 & & 2 & 60.5 & 9.2 & \\
\hline Edo & 30 & 62.8 & 8.4 & $\mathbf{J}$ & 30 & 6.7 & 4.5 & & 23 & 51.7 & 8.5 & $\mathrm{~J}$ \\
\hline Recent & 16 & 63.4 & 6.3 & $\mathrm{~J}$ & 16 & 8.0 & 3.9 & & 12 & 50.3 & 10.1 & $\mathrm{~J}$ \\
\hline
\end{tabular}


Table 3b (continued)

\begin{tabular}{|c|c|c|c|c|c|c|c|c|c|c|c|c|}
\hline & \multicolumn{4}{|c|}{$\begin{array}{c}\mathrm{C}^{1} \text { inclination angle } \\
\mathrm{F}=4.82, \mathrm{P}=0.00\end{array}$} & \multicolumn{4}{|c|}{$\begin{array}{l}\mathrm{I}_{1} \text { inclination angle } \\
\mathrm{F}=2.14, \mathrm{P}=0.06\end{array}$} & \multicolumn{4}{|c|}{$\begin{array}{c}\mathrm{C}_{1} \text { inclination angle } \\
\mathrm{F}=2.03, \mathrm{P}=0.08\end{array}$} \\
\hline & $\mathrm{N}$ & Mean & S.D. & $\begin{array}{l}\text { Pops. with } \\
\text { signif. diff. }^{\text {b }}\end{array}$ & $\mathrm{N}$ & Mean & S.D. & $\begin{array}{l}\text { Pops. with } \\
\text { signif. diff. }^{\text {b }}\end{array}$ & $\mathrm{N}$ & Mean & S.D. & $\begin{array}{l}\text { Pops. with } \\
\text { signif. diff. }^{\text {b }}\end{array}$ \\
\hline Jomon & 15 & 76.6 & 6.0 & All but $\mathrm{M}$ & 11 & 80.3 & 6.6 & & 13 & 84.1 & 6.6 & \\
\hline Yayoi & 15 & 69.8 & 5.2 & $\mathrm{~J}$ & 7 & 77.0 & 11.2 & & 8 & 75.8 & 8.3 & \\
\hline Kofun & 5 & 67.1 & 5.7 & $\mathrm{~J}$ & 2 & 81.0 & 5.7 & & 2 & 86.0 & 1.4 & \\
\hline Kamakura & 18 & 70.2 & 6.7 & $\mathrm{~J}$ & 6 & 70.1 & 5.8 & & 9 & 79.4 & 6.9 & \\
\hline Muromachi & 2 & 73.5 & 5.0 & & 1 & 65.0 & - & & 1 & 75.0 & - & \\
\hline Edo & 26 & 66.6 & 6.4 & $\mathrm{~J}$ & 23 & 71.0 & 9.8 & & 24 & 79.5 & 6.8 & \\
\hline \multirow[t]{3}{*}{ Recent } & 10 & 68.0 & 5.1 & $\mathrm{~J}$ & 11 & 75.3 & 8.2 & & 10 & 84.2 & 7.7 & \\
\hline & \multicolumn{4}{|c|}{$\begin{array}{c}\text { Inter-insical angle } \\
F=7.67, P=0.00\end{array}$} & \multicolumn{4}{|c|}{$\begin{array}{l}\text { Inter-canine angle } \\
\mathrm{F}=3.18, \mathrm{P}=0.01\end{array}$} & \multicolumn{4}{|c|}{$\begin{array}{c}\left(\mathrm{I}^{1} \text { inc. ang. }\right)-\left(\mathrm{I}_{1} \text { inc. ang. }\right) \\
\mathrm{F}=3.19 \mathrm{P}=0.01\end{array}$} \\
\hline & $\mathrm{N}$ & Mean & S.D. & $\begin{array}{l}\text { Pops. with } \\
\text { signif. diff. }^{\mathrm{b}}\end{array}$ & $\mathrm{N}$ & Mean & S.D. & $\begin{array}{l}\text { Pops. with } \\
\text { signif. diff. }\end{array}$ & $\mathrm{N}$ & Mean & S.D. & $\begin{array}{l}\text { Pops. with } \\
\text { signif. diff. }\end{array}$ \\
\hline Jomon & 10 & 149.9 & 13.0 & $\mathrm{Y}, \mathrm{Ka}, \mathrm{E}, \mathrm{R}$ & 12 & 157.0 & 10.3 & $\mathrm{E}$ & 10 & 6.4 & 12.6 & $\mathrm{R}$ \\
\hline Yayoi & 7 & 127.0 & 18.8 & $\mathbf{J}$ & 7 & 141.4 & 13.3 & & 7 & 22.5 & 7.7 & \\
\hline Kofun & 2 & 132.8 & 4.6 & & 2 & 140.3 & 5.3 & & 2 & 22.3 & 12.4 & \\
\hline Kamakura & 6 & 113.6 & 6.4 & $\mathrm{~J}$ & 9 & 140.6 & 8.8 & & 6 & 17.3 & 9.6 & \\
\hline Muromachi & 1 & 130.5 & - & & 1 & 151.5 & - & & 1 & -2.0 & & \\
\hline Edo & 20 & 114.7 & 14.8 & $\mathrm{~J}$ & 22 & 133.6 & 21.3 & $\mathrm{~J}$ & 20 & 18.1 & 11.0 & \\
\hline \multirow[t]{3}{*}{ Recent } & 8 & 121.6 & 15.0 & $\mathrm{~J}$ & 7 & 148.1 & 9.5 & & 8 & 24.9 & 11.4 & $\mathrm{~J}$ \\
\hline & \multicolumn{4}{|c|}{$\begin{array}{c}\left(\mathrm{C}^{1} \text { inc. ang. }\right)-\left(\mathrm{C}_{1} \text { inc. ang. }\right) \\
\mathrm{F}=2.63, \mathrm{P}=0.03\end{array}$} & \multicolumn{4}{|c|}{$\begin{array}{l}\text { AAL1/UIL angle } \\
\mathrm{F}=9.05, \mathrm{P}=0.00\end{array}$} & \multicolumn{4}{|c|}{$\begin{array}{l}\text { AAL2/UIL angle } \\
\mathrm{F}=3.11, \mathrm{P}=0.01\end{array}$} \\
\hline & $\mathrm{N}$ & Mean & S.D. & $\begin{array}{l}\text { Pops. with } \\
\text { signif. diff. }\end{array}$ & $\mathrm{N}$ & Mean & S.D. & $\begin{array}{l}\text { Pops. with } \\
\text { signif. diff. }\end{array}$ & $\mathrm{N}$ & Mean & S.D. & $\begin{array}{l}\text { Pops. with } \\
\text { signif. diff. }\end{array}$ \\
\hline Jomon & 12 & 7.4 & 10.5 & & 14 & 15.9 & 10.3 & All but $\mathrm{M}$ & 11 & 5.8 & 8.9 & $\mathrm{Y}, \mathrm{E}, \mathrm{R}$ \\
\hline Yayoi & 7 & 8.5 & 3.4 & & 15 & 1.4 & 5.9 & $\mathrm{~J}$ & 12 & -4.3 & 6.6 & $\mathrm{~J}$ \\
\hline Kofun & 2 & 24.8 & 2.5 & & 4 & -2.1 & 3.3 & $\mathrm{~J}$ & 4 & -4.0 & 2.0 & \\
\hline Kamakura & 9 & 9.4 & 8.0 & & 16 & 1.0 & 6.9 & $\mathrm{~J}$ & 15 & -1.2 & 6.0 & \\
\hline Muromachi & 1 & -2.0 & - & & 2 & 9.0 & 5.7 & & 2 & -0.3 & 6.0 & \\
\hline Edo & 22 & 12.0 & 8.3 & & 23 & -1.4 & 6.6 & $\mathrm{~J}$ & 23 & -3.2 & 6.6 & $\mathrm{~J}$ \\
\hline Recent & 7 & 17.1 & 7.1 & & 12 & -3.7 & 11.8 & $\mathrm{~J}$ & 12 & -5.3 & 8.5 & $\mathrm{~J}$ \\
\hline
\end{tabular}

See Table3a for notes. 

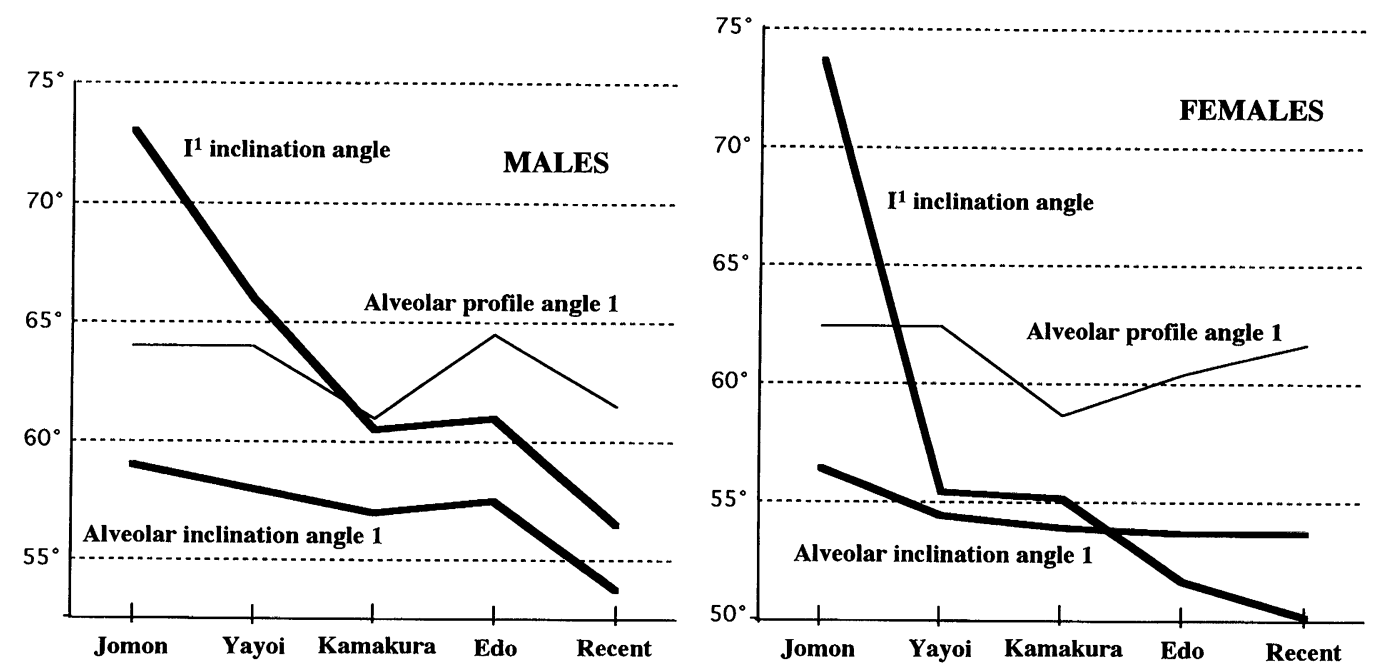

Figure 3 Comparison of the means of alveolar inclination angle 1, alveolar profile angle 1, and $I^{1}$ inclination angle among five Japaenese populations.

the Yayoi, Edo, and Recent in both sexes (the Kofun is small in sample size).

The means of $I^{1}$ inclination angle show the following pattern of changes: Jomon $>>$ Yayoi $>($ Kofun $=)$ Kamakura $(=$ Muromachi $)=$ Edo $>$ Recent in the males, and Jomon $>$ Yayoi $(=$ Kofun $)=$ Kamakura $(=$ Muromachi $)>$ Edo $=$ Recent in the females. Similar patterns of changes, in that generally the Jomon is larger than the others and the Recent is the least, are also observed in the $C^{1}$ inclination angle, $I_{1}$ inclination angle, and $C_{1}$ inclination angle. The degree of temporal changes in these measurements are, however, smaller compared to those observed in the $I^{1}$ inclination angle. As for the sex differences in the above four measurements, the females tend to be smaller than the males in general. As for $I^{1}$ inclination angle, t-tests show significant or nearly significant sex differences in the Yayoi, Kamakura, Edo, and Recent samples.

The inter-incisal angle and inter-canine angle are the largest in the Jomon and tend to decrease through time thereafter. The range of these temporal changes is larger in the I1 than in the $\mathrm{C}$. As seen in the differences between $I^{1}$ inclination angle and $I_{1}$ inclination angle, and those between $C^{1}$ inclination angle and $C_{1}$ inclination angle, the maxillary teeth are more protrusive than their mandibular antagonists are in every temporal group. There are inter-group differences in the magnitude of this between-jaw difference as follows: Jomon $<$ Yayoi $=$ Kamakura $<$ Edo $<$ Recent (the Kofun and Muromachi were excluded because of small sample sizes).

Comparison of the angle formed by the anterior surface of the maxillary alveolar bone and $\mathrm{I}^{1}$ (AAL1/UIL angle and AAL2/UIL angle) indicates that the $\mathrm{I}^{1}$ of the Jomon faces downward relative to the inclination of the anterior surface of the alveolar process. In the 
Table 4 Correlation coefficients ${ }^{\mathrm{a}}$

\begin{tabular}{lccccc}
\hline & \multicolumn{2}{c}{ Males } & & \multicolumn{2}{c}{ Females } \\
\cline { 2 - 3 } \cline { 5 - 6 } \multicolumn{1}{c}{ Alveolar } & Pearson & Spearman & & Pearson & Spearman \\
Jomon & $0.69(39)^{* *}$ & $0.71(39)^{* *}$ & & $0.14(14)$ & $0.18(14)$ \\
Yayoi & $0.41(23)^{*}$ & $0.44(23)^{*}$ & & $0.53(15)^{*}$ & $0.38(15)$ \\
Kamakura & $0.59(46)^{* *}$ & $0.60(46)^{* *}$ & & $0.59(16)^{*}$ & $0.36(16)$ \\
Edo & $0.46(34)^{* *}$ & $0.43(34)^{* *}$ & & $0.63(23)^{* *}$ & $0.63(23)^{* *}$ \\
Recent & $0.46(27)^{*}$ & $0.24(27)$ & & $-0.38(12)$ & $-0.21(12)$ \\
$\quad I^{1}$ inclination & angle $\times$ cranial & index & & & \\
Jomon & $-0.03(30)$ & $-0.07(30)$ & & $-0.18(12)$ & $0.06(12)$ \\
Yayoi & $0.00(16)$ & $-0.31(16)$ & & $0.24(9)$ & $0.12(9)$ \\
Kamakura & $-0.28(29)$ & $-0.31(29)$ & & $0.38(11)$ & $0.17(11)$ \\
Edo & $0.02(31)$ & $0.03(31)$ & & $0.12(22)$ & $0.07(22)$ \\
Recent & $0.22(26)$ & $0.18(26)$ & & $-0.11(12)$ & $-0.04(12)$ \\
\hline
\end{tabular}

${ }^{\mathrm{a}} \mathrm{N}$ of pairs in parentheses.

*, **: significantly larger than 0 at the level of 0.05 and 0.01 .

other groups, the $\mathrm{I}^{1}$ shows a similar or more protrusive condition relative to the inclination of the alveolar process, although there is a slight degree of sex difference in this trait (see Figure 2). The Yayoi males are somewhat exceptional for this tendency showing a condition slightly closer to the Jomon.

Table 4 shows the correlation coefficients between alveolar inclination angle 1 and $I^{1}$ inclination angle for groups with a relatively large sample size. Moderate degree of correlation between these measurements is seen in most of these groups.

\section{Discussion}

Temporal changes of alveolar prognathism and anterior teeth protrusion in Japan

Alveolar profile angle ( 1 and 2 ), which utilizes the $F H$ as a reference line, showed a similar pattern of temporal changes as those detected in the previous studies (Suzuki, 1956a, 1969; Nakahashi, 1993), which based their argument on the angular measurements relative to the $F H$ (alveolar profile angle in Martin, 1928). The group means of these measurements generally dip in the Medieval era. The results of the alveolar inclination angle (1 and 2) were, however, different from them and showed generally the following pattern of changes: Jomon $\geqq$ Yayoi $=$ Kofun $=$ Kamakura $=$ Muromachi $=$ Edo $\geqq$ Recent. On the other hand, the Jomon, Kofun, Kamakura, and Muromachi were smaller in the angle formed between the $F H$ and upper alveolar line ( $F H / U A L$ angle) than the Yayoi, Edo, and Recent. Although this tendency is subtle, the fact that similar tendencies were observed in both sexes seems to indicate the existence of real inter-group differences. The above results leads to a conclusion that the results of the previous studies reflect the 
combined effect of changes in alveolar prognathism relative to the upper alveolar line and inter-group differences in the angle between the $F H$ and upper alveolar line. If the alveolar prognathism is defined as the inclination of the maxillary alveolar process relative to the upper alveolar line that approximate the tooth row in lateral view (see above), then the changes of it in Japan is more properly reflected in the changes in the alveolar inclination angle ( 1 and 2 ) of this study.

The cause of temporal changes in $F H / U A L$ angle detected here is unknown at the present stage. One possible interpretation for this change is as follows. There are inherent differences in the expression of $F H / U A L$ angle between the Jomon and immigrant Yayoi populations (the former is smaller than the latter). The FH/UAL angle increased, in the Kanto region, in the populations after the Edo period as a result of intensified genetic influence from the immigrant Yayoi people in the Edo period and afterward. This scenario on the genesis of the Japanese populations in east Japan is supported by a study on mandibular morphology (Kaifu, 1997). Many other studies, however, suggest that the genetic contribution from the immigrant Yayoi people in the Kanto region had already exceeded that from the native Jomon people by the Kofun period (Dodo and Ishida, 1990, 1992; Matsumura, 1994). The changes in the Kyushu region must be examined before discussing the above possibility further.

The pattern of temporal changes in anterior teeth protrusion relative to the alveolar lines detected in this study can be summarized as follows: The anterior teeth are more vertically arranged in the Jomon people, while in the Yayoi and later populations examined, the anterior teeth tend to be more protrusive. This tendency seen in the Yayoi and later populations is especially marked in the maxillary rather than the mandibular teeth, and so in mesially rather than distally located teeth. The changes in the protrusion of the $\mathrm{I}^{1}$ after the Yayoi period are relatively subtle but the following pattern is recognized: Yayoi $<$ Kamakura $=$ Edo $<$ Recent in the males, and Yayoi $=$ Kamakura $<$ Edo $=$ Recent in the females.

A certain degree of relevancy evidently exists between alveolar prognathism (relative to the alveolar lines) and anterior teeth protrusion since they show a moderate degree of correlation within each chronological group (Table 4). However, the correlation between the two measurements is not high in terms of inter-temporal group comparisons (Figure 3). While the $I^{1}$ shows drastic changes toward protrusive condition through time, the range of changes detected in the alveolar prognathism is subtle. This is also reflected in the changes in the $A A L 1 /$ UIL angle and $A A L 2 /$ UIL angle. Therefore, changes in alveolar prognathism should not be regarded as identical with changes in anterior teeth protrusion (see Figure 2).

In every temporal group examined, the females showed a more protrusive tendency compared to the males in both alveolar prognathism and anterior teeth protrusion. Nakahashi and Nagai (1985) pointed out, through an investigation of their own and published data, that a similar sex difference is recognized in medieval populations from Kyushu and surrounding regions as well as in recent populations from various parts of 
Japan. This pattern of sexual dimorphism in Japan is consistent with that demonstrated in many other populations in the world (Wei, 1968).

\section{Peculiarity of the Kamakura population}

The Kamakura people have been regarded to be somewhat peculiar among Japanese populations of various periods in having a markedly dolichochephalic cranium, strong alveolar prognathism (anterior teeth protrusion), and a flat nasal bridge. This view was developed in the pioneering works of Suzuki (1956a, b, 1963, 1969, 1981), and has been followed until today (for example, Yamaguchi, 1986; Matsushita, 1994; Dodo, 1995).

The present study confirmed peculiarity of the Kamakura population in terms of alveolar prognathism relative to the $F H$; this population generally showed the smallest mean value in alveolar profile angle (1 and 2) among the comparative samples. However, this study also revealed that the pattern of changes in alveolar prognathism from the Jomon period onwards is, when it is measured relative to the upper alveolar line, a nearly monotonous decrease. These results urge reconsideration of the previous view on alveolar prognathism that has been based only on the measurements relative to the FH. That is, although the Kamakura population is peculiar in alveolar profile angle, this fact can not necessarily be regarded as indicating peculiarity of this population in alveolar prognathism. The interpretation of the later depends on the choice of reference lines.

\section{Cause of temporal changes in anterior teeth protrusion}

The temporal changes in anterior teeth protrusion in Japan are very drastic compared to those in alveolar prognathism. In this section, causative factors of the changes in the former are discussed.

Among possible environmental causes of strong anterior teeth protrusion pointed out in dentistry are: finger sucking, lip sucking, habitual mouth breathing, abnormal tongue habits, abnormal swallowing habits, microgenia, macroglossia, and decrease of the occlusal height due to destruction of the crown or tooth loss caused by dental diseases (Yamauchi, 1981). All of these are, however, types of abnormal habitat or disease and hence can hardly explain the population-level changes detected here.

Is it possible to explain these changes in terms of changes in genetic composition, that is, by mixture or replacement of populations? Application of this view to the present data leads to the following working hypothesis: strong anterior teeth protrusion was an inherent feature of the immigrant Yayoi people and this was succeeded by the Kofun and later populations in the Kanto region by overwhelming gene flow from the former over the native Jomon lineage. Although this factor may have played a role, the whole aspect of the changes in anterior teeth protrusion cannot be explained by this factor alone. First, such a replacement model in Japanese population history is rejected from various evidence (for example, Hanihara, 1991; Omoto and Saitou, 1997). Moreover, the anterior teeth protrusion is weaker in the Yayoi immigrant people than in the Kofun 
population in the Kanto, and it becomes even stronger after the Kofun period toward modern times.

The most popular hypothesis explaining the temporal changes in anterior teeth protrusion is probably the one that relates these changes to the reduction of masticatory activities (Suzuki, 1967, 1985a, b; Kamegai and others, 1982; Baba and Etoh, 1989). Various views concerned with this hypothesis can be integrated as follows. Tooth size is relatively strongly determined by inheritance and never changes drastically across generations. On the other hand, recent cultural development leads to a reduction in masticatory activities causing underdevelopment of the jaw bone, because the jaw bone needs a certain degree of mechanical stimulation to grow properly. As a result, while the supporting bone reduces, the anterior teeth remain essentially unchanged in their size and protrude forward.

This study shows that considerably marked anterior teeth protrusion appeared in the Kanto region at least by the Kofun period. On the other hand, an analyses on the mandibles of almost the same sample as in the present study indicated that clear mandibular reduction probably due to underdevelopment appeared in the Edo and later periods (Kaifu, 1997). This interpretation of mandibular change is supported by the fact that cooking methods have been drastically changed during the Edo period (Seguchi, 1998), as well as by the pattern of temporal changes in tooth wear severity on the posterior teeth (Kaifu, submitted). Therefore, while this factor may affect populations of the Edo and later periods, it cannot explain the drastic changes that occurred before medieval times.

Sakai (1954) found a positive correlation between incisor shoveling and labial overjet in a modern Japanese population. In connection with this report, Mizoguchi (1985) pointed out that, in the case of incisor overlapping, the maxillary anterior teeth of an individual with developed marginal ridges might be subject to upward pressure from their antagonists in the mandible. Another interpretation for Sakai's observation is as follows. Modern Japanese are considered to be formed through a mixture of native Jomon and Yayoi immigrant people, as mentioned above. The latter is characterized by greater tooth size and developed shoveling, the former by smaller tooth size and weak shoveling (Matsumura, 1994). Consequently, if there is a significant correlation between anterior teeth protrusion and shoveling in Japanese populations, it may be attributed to inter-populational variation in tooth size and the population history of Japan.

Thus, existence of correlation between anterior teeth protrusion and shoveling cannot be theoretically denied. However, although the frequency of shoveling incisors becomes abruptly high in the Kofun period in the Kanto region according to Matsumura (1994), relatively stable changes thereafter do not explain the slight intensification in anterior teeth protrusion in historic times. In addition, Sakai's report is based on observations in a single population and it does not indicate that the same tendency is to be observed in between-population comparisons. For example, alveolar prognathism and anterior teeth protrusion are weak in Inuits who are characterized by developed shoveling (Hylander, 
1977a), while these traits are relatively strong in the Ainu who do not show developed shoveling (Yamaguchi, 1981; Kaifu, personal observation). Therefore, it is unreasonable to attribute temporal changes in anterior teeth protrusion to variation in the development of shoveling.

Although rejected by the present study, it has been assumed that dolicocephaly and strong alveolar prognathism or anterior teeth protrusion were two of the major characteristic features of the Kamakura people. Because of this, correlation coefficients were calculated between the cranial index and $I^{1}$ inclination angle within each group to examine their relevancy. The results (Table 4) show that the correlation is not significant in any temporal group and there is no consistency in plus and minus signs of them. Therefore, head form and anterior teeth protrusion can be regarded as independent each other.

Through an analysis of gnatho-facial morphology of a modern Swedish sample, Björk (1947) pointed out several possible causative factors on the variation of prognathism. Anterior cranial base length (nasion-sella), cranial base flexure, the angle formed by cranial base and mandibular ramus, antero-posterior length of the jaws are some of them. This suggests that temporal changes in anterior teeth protrusion may be attributable to temporal changes in these traits. However, as information relevant to this issue is limited for Japanese skeletal series, a discussion will not be attempted here.

An interesting matter appears if one looks at the occlusal relationship of the anterior teeth. Japanese populations in historic times show incisor overlapping (scissor bite) in almost all cases while edge-to-edge bite is the dominant form in the Jomon people (Suzuki, 1969; Seguchi, 1998; Kaifu, unpublished data). It is obvious that these differences in bite form affect the degree of anterior teeth protrusion. The presently demonstrated fact that anterior teeth protrusion in historic populations is especially marked in the maxillary teeth rather than in the mandibular teeth (Table 3 and Figure 2 ) is consistent with the above view. Transition of the bite form is shown to be strongly dependent on the state of tooth wear, especially wear on the anterior teeth (see Kaifu, 1996). In addition, uprighting movement of the central incisors with the advance of wear is documented in several past populations showing severe occlusal wear (Lysell and Fillipson, 1958; Hasund, 1965; Hylander, 1977b). This also strongly suggests that variation in anterior teeth protrusion is dependent on severity of wear. This possibility will be examined in depth in another paper (Kaifu, in preparation).

\section{Conclusions}

1. Alveolar prognathism, when measured relative to the alveolar lines, showed a limited but nearly monotonous increase during the past circa 2,300 years in Japan.

2. The anterior teeth are much more upright in the Jomon people than in the Yayoi immigrant population and later populations in the Kanto region. The changes after the Yayoi period are limited but the anterior teeth tend to become generally more protrusive through time. 
3. Although the patterns of temporal changes in Japan in alveolar prognathism and anterior teeth protrusion are similar, they are not identical in terms of the amount of change, being the latter more drastic than the former.

4. The females tend to be greater than the males in the degree of alveolar prognathism and anterior teeth protrusion in Japanese populations at any period.

\section{Acknowledgments}

I express my gratitude to Dr. Gen Suwa and Prof. Yoshiyuki Tanaka for their permission to investigate the materials in their care. I am greatly indebted to Dr. Gen Suwa for invaluable suggestions. Thanks are also due to Dr. Kazutaka Adachi, Prof. Kazutaka Kasai, and Dr. Mark J. Hudson for helpful comments. This study was supported by Grant-in-Aid for Scientific Research, Ministry of Education, Science, Sports and Culture (No. 09740651).

\section{REFERENCES}

Anneroth G. and Ericsson S.G. (1967) An experimental histological study of monkey teeth without antagonist. Odontologisk Revy, vol. 18, pp. 345-359.

Argyropoulos E, Sassouni V, and Xeniotou A. (1989) A comparative cephalometric investigation of the Greek craniofacial pattern through 4,000 years. Angle Orthodontist, vol. 59, pp. 195-204.

Baba H. and Etoh M. (1989) On the human skeletal remains of the Jomon people from eastern Japan. In Etoh M.. ed., "A study on the morphological variation of human skeletal remains of Jomon period from eastern Japan”, A Report of the Research Supported by a Grant-in Aid for Scientific Research from the Japanese of Education, Science and Culture, Japan, pp. 3-14 (in Japanese).

Björk A. (1947) The face in profile. Svensk Tandläkare-Tidskrift, vol. 40, Supplement. Brues A.M. (1977) People and races. Waveland Press, Illinois.

Compagnon D. and Wada A. (1991) Supraeruption of the unopposed maxillary first molar. Journal of Prosthetic Dentistry, vol. 66, pp. 29-34.

Dodo Y. (1982) A metrical analysis of Jomon crania from the Tohoku district. Journal of Anthropological Society of Nippon, vol. 90, pp. 119-128 (in Japanese with English summary).

Dodo Y. (1986) Metrical and non-metrical analyses of Jomon crania from eastern Japan. In Akazawa T. and Aikens M. eds., "Prehistoric hunter-gatherers in Japan: New research method", University Museum Bulletin, The University of Tokyo, vol. 27, pp. 137-161.

Dodo Y. (1995) Population history of Japan as viewed from skeletal morphology. In Dodo Y. ed., “The Mongoloid World”, University of Tokyo Press, Tokyo, pp. 129-171 (in Japanese).

Dodo Y. and Ishida H. (1990) Population history of Japan as viewed from cranial nonmetric variation. Journal of the Anthropological Society of Nippon, vol. 98, pp. 
269-287.

Dodo Y. and Ishida H. (1992) Consistency of nonmetric cranial traits expression during the last 2,000 years in the habitants of the central islands of Japan. Journal of the Anthropological Society of Nippon, vol. 100, pp. 417-423.

Hanihara K. (1991) Dual structure model for the population history of the Japanese. Japan Review, vol. 2, pp. 1-33.

Hasund A.P. (1965) Attrition and dental arch space. Transaction of European Orthodontic Society, vol. 41, pp. 121-131.

Hooton E.A. (1946) Up from the ape. The Macmillian Company, New York.

Hylander W.L. (1977a) The adaptive significance of Eskimo craniofacial morphology. In Dahlberg A.A. and Graber T.M. eds., "Orofacial growth and development", Mouton Publishers, Paris, pp. 129-169.

Hylander W.L. (1977b) Morphological changes in human teeth and jaws in a highattrition environment. In Dahlberg A.A. and Graber T.M. eds., "Orofacial growth and development”, Mouton Publishers, Paris, pp. 301-333.

Kaifu Y. (1995) Regional variation in mandibular morphology of the Jomon people. Bulletin of the National Science Museum, Tokyo, Series D, vol. 21, pp. 37-50.

Kaifu Y. (1996) Edge-to-edge bite and tooth wear. Bulletin of the National Science Museum, Tokyo, Series D, vol. 22, pp. 45-54.

Kaifu Y. (1997) Changes in mandibular morphology from the Jomon to modern periods in eastern Japan. American Journal of Physical Anthropology, vol. 104, pp. 227-243.

Kaifu Y. (1999) Temporal change in tooth wear in Japan. Anthropological Science, vol. 107, no. 1, p. 50.

Kaifu Y., Nakahashi T., and Hashimoto H. (1998) Morphology of the Jomon skeletal remains from Kyushu: On the collection housed in The University Museum, The University of Tokyo. Memoirs of the National Science Museum, No. 30, pp. 185-198.

Kamegai T., Kuragano S., and Hanihara K. (1982) Secular change of dentofacial morphology during Japanese historic ages. Journal of the Anthropological Society of Nippon, vol. 90, pp. 303-314.

Lysell L. and Filipsson R. (1958) A profile roentogenologic study of a series of medieval skulls from northern Sweden. Odontologisk Tidskrift, vol. 66, pp. 161-174.

Martin R. (1928) Lehrbuch der Anthropologie. 2. Aufl. G. Fischer, Jena.

Matsumura H. (1989) Geographical variation of dental measurements in the Jomon population. Journal of the Anthropological Society of Nippon, vol. 97, pp. 493-512.

Matsumura H. (1994) A microevolutional history of the Japanese people from a dental characteristics perspective. Anthropological Science, vol. 102, pp. 93-118.

Matsushita T. (1994) Japanese and Yayoi people. Shoudensha, Tokyo (in Japanese).

Mikami T. (1956) On the age of the human skeletons from the Zaimokuza site in Kamakura. In Anthropological Society of Nippon ed., "Medieval Japanese skeletons from the burial site at Zaimokuza, Kamakura City", Iwanami-shoten, Tokyo, pp. 67-74 (in Japanese with English summary). 
Mizoguchi Y. (1985) Shovelling: A statistical analysis of its morphology. University Museum Bulletin, The University of Tokyo, vol. 26.

Montagu A. (1960) An introduction to physical anthropology. 3rd ed. Charles C Thomas, Springfield, Illinois.

Mouri T. (1988) Incidences of cranial nonmetric characters in five Jomon populations from west Japan. Journal of the Anthropological Society of Nippon, vol. 96, pp. 319-337.

Naito Y. and Matsushita T. (1977) Anthropological study on the skeletons of Jomon period in Kyushu. Acta Anatomica Nipponica, vol. 52, pp. 117 (in Japanese).

Nakahashi T. (1993) Temporal craniometric changes from the Jomon to Modern period in western Japan. Americal Journal of Physical Anthropology, vol. 90, pp. 409-425.

Nakahashi T. and Iizuka M. (1998) Anthropological study of the transition from the Jomon to the Yayoi periods in northern Kyuhu using morphological and paleodemographical features. Anthropological Science Japanese Series, vol. 106, pp. 31-53 (in Japanse with English summary).

Nakahashi T. and Nagai M. (1985) Human skeletal remains of the Yayoi period and Medieval Era excavated from the Yoshimohama site. In "Yoshimohama site", Educational Committee of Shimonoseki City, pp. 154-225 (in Japanese).

Omoto K. and Saitou N. (1997) Genetic origins of the modern Japanese: A partial support for the dual structure hypothesis. American Journal of Physical Anthropology, vol. 102, pp. 437-446.

Sakai T. (1954) Shovel-shaped incisors in the Japanese. The Shinshu Medical Journal, vol. 3, pp. 23-27 (in Japanese).

Sakuma M. (1987) Anthropological study of medieval crania from the Kyushu district. The Nagasaki Medical Journal, vol. 61, pp. 4-21.

Seguchi N. (1998) Secular change of Japanese occlusion: The frequency of the overbite and its association with food preparation techniques and eating habits. American Journal of Physical Anthropology, Vol. 26, Supplement, p. 199.

Suzuki H. (1956a) Changes in the skull features of the Japanese people from ancient to modern times. In "Selected papers of the Vth international congress of anthropological and ethnological sciences", University of Phennsylvania Press, Philadelphia, pp. 717724.

Suzuki H. (1956b) Discussion. In Anthropological Society of Nippon ed., "Medieval Japanese skeletons from the burial site at Zaimokuza, Kamakura City", Iwanamishoten, Tokyo, pp. 155-168 (in Japanese with English summary).

Suzuki H. (1963) Skeleton of the Japanese. Iwanamishoten, Tokyo.

Suzuki H. (1967) VI. Skull. In Suzuki H., Yajima, K., and Yamanobe T. eds., "Studies on the graves, coffin contents and skeletal remains of the Tokugawa Shoguns and their femilies at the Zojoji Temple", University of Tokyo Press, Tokyo, pp. 121-274 (in Japanese with English summary).

Suzuki H. (1969) Microevolutional changes in the Japanese population from the prehistoric 
age to the present-day. Journal of Faculty of Science, the University of Tokyo, Section V 3, pp. 279-309.

Suzuki H. (1981) Racial history of the Japanese. In Schwidetzky I. ed., "Rassengeschichte der Menscheit. 8. Lieferung. Asien I: Japan, Indonesien, Ozeanien”, Oldenbourg Verlag, München pp. 7-69.

Suzuki H. (1985a) Manifestation of the physical characteristics of Japanese aristocrats in the Edo era of Japan. Journal of the Anthropological Society of Nippon, vol. 93, pp. 1-32 (in Japanese with English summary).

Suzuki H. (1985b) What the bone tell us: People in the Tokugawa shogun and feudal lord families. Tokyo University Press, Tokyo.

Terakado Y. (1981) Skeletal remains from the Kofun period. In Ogata T. ed., "Japanese 1, jinruigaku koza 5”, Yuzankaku-shuppan, Tokyo, pp. 101-121 (in Japanese).

Varrela J. (1990) Effects of attritive diet on craniofacial morphology: a cephalometric analysis of a Finnish skull sample. European Journal of Orthodontics, vol. 12, pp. 219-223.

Wei S.H.Y. (1968) A roentogenographic cephalometric study of prognathism in Chinese males and females. Angle Orthodontist, vol. 38, pp. 305-321.

Wolpoff M. and Caspari R. (1996) Race and human evolution. Simon \& Schuster, New York.

Yamaguchi B. (1981) Human skeletal remains from Hokkaido. In Ogata T. ed., "Japanese 1, jinruigaku-koza 5”, Yuzankaku-shuppan, Tokyo, pp. 137-156 (in Japanese).

Yamaguchi B. (1982) A review of the osteological characteristics of the Jomon population in prehistoric Japan. Journal of the Anthropological Society of Nippon, vol. 90, Supplement, pp. 77-90.

Yamaguchi B. (1986) Face and body of the Japanese. PHP Kenkyusho, Tokyo.

Yamaguchi B. (1989) Limb segment proportions in human skeletal remains of the Jomon period. Bulletin of the National Science Museum, Tokyo, Series D, vol. 15, pp. 41-48. Yamaguchi B. (1997) Chronological and regional variations in the alveolar profile angle. In "Proceedings of 51th annual meeting of the Anthropological Society of Nippon", p. 65 (in Japanese).

Yamauchi K. (1981) On the acquired causes of maxillary protrusion. In Yamauchi K. and Sakuta M. eds., “Maxillary protrusion”, Ishiyaku-shuppan, Tokyo, pp. 81-91.

Handling editor: Ishida Hajime 